American Journal of Pharmaceutical Education 2021; 85 (5) Article 8311.

\title{
COMMENTARY
}

\section{Addressing the Challenges of Precepting Students Enrolled in Remote Research Advanced Pharmacy Practice Experiences}

\author{
Anisha K. Hundal, HBSc, ${ }^{a}$ Taylor L. Watterson, PharmD, MS, ${ }^{b}$ Kaleen N. Hayes, PharmD ${ }^{\mathrm{a}, \mathrm{c}}$ \\ ${ }^{a}$ University of Toronto, Leslie Dan Faculty of Pharmacy, Toronto, Ontario, Canada \\ ${ }^{\mathrm{b}}$ University of Wisconsin-Madison, School of Pharmacy, Madison, Wisconsin \\ ${ }^{\text {c }}$ University of Toronto, Dalla Lana School of Public Health, Toronto, Ontario, Canada
}

Submitted July 27, 2020; accepted December 22, 2020; published May 2021.

\begin{abstract}
As a result of restrictions imposed by COVID-19, many researchers have responded to the call for remote, advanced pharmacy practice experiences (APPEs) that do not involve direct patient care. The influx of materials on online pedagogy may be difficult for new preceptors to digest while familiarizing themselves with the APPE program. To complement the available guidance on remote learning for new preceptors, we describe our experiences with implementing a remote, research-focused APPE during COVID-19. Common challenges are discussed and potential solutions that may help new preceptors anticipate and overcome barriers to achieving the educational outcomes of researchfocused APPE are proposed.
\end{abstract}

Keywords: COVID-19, experiential education, remote, virtual learning

\section{INTRODUCTION}

In response to the abrupt halt of in-person instruction in early 2020 to mitigate the transmission of COVID-19, ${ }^{1}$ health professions programs have been required to adapt their methods of instruction. ${ }^{2-5}$ For students in the experiential portion of their programs, temporary reforms have resulted in the minimization of direct patient contact to reduce student exposure to COVID-19. Moreover, the call for clinical faculty to come to the frontlines of the epidemic to assist with treating COVID-19 patients, as well as the need to conserve personal protective equipment (PPE), has substantially limited the number of clinical experiences available to students. ${ }^{2}$

For Doctor of Pharmacy (PharmD) programs, measures to mitigate COVID-19 exposure have profoundly influenced the structure of advanced pharmacy practice experience (APPE). Advanced experiences are completed in the final year of the PharmD curriculum and provide student pharmacists with opportunities to practically apply the knowledge they have learned in professional settings. ${ }^{6}$ In response to COVID-19, colleges of pharmacy have released calls for non-direct patient care, remote APPEs. ${ }^{7}$ Dry-laboratory, research-focused APPEs are not only well-positioned to respond to this acute need to provide remote APPEs, but also help fulfill Accreditation

Corresponding Author: Kaleen Hayes, University of

Toronto, Leslie Dan Faculty of Pharmacy, 144 College St., Toronto, ON, Canada M5S 3M2. Tel: +1-647-383-6768.

Email: k.hayes@mail.utoronto.ca
Council for Pharmacy Education (ACPE) educational outcomes and standards, including student pharmacists' competency in problem solving, interprofessional collaboration, communication, and personal and professional development. ${ }^{6,8}$ However, faculty may perceive several challenges to precepting APPE students, such as lack of time to fulfill educational outcomes because of high workload and low student interest in research. ${ }^{9}$ Requirements for online precepting, rapid conceptualization of research projects that fit within APPE timeframes, and increased personal responsibilities for preceptors and students alike during the COVID-19 pandemic amplify these challenges.

University administration and learning centers have distributed a plethora of guidance regarding online pedagogy. Although helpful in familiarizing preceptors with general remote-learning strategies, the volume of material available may be overwhelming. Providing a thoughtful account of the challenges we encountered during the first remote research APPEs conducted during the pandemic, in conjunction with formalized pedagogical guidance, may help new preceptors gain insight into specific challenges presented by the virtual research environment and set students up for success during their research-focused APPE. The purpose of this article is to share our clinical researcher and student experience in engaging in remote, research-focused APPE learning and propose mitigation strategies for possible challenges that also may be useful for other APPEs, including patient care rotations with a remote component. 


\section{American Journal of Pharmaceutical Education 2021; 85 (5) Article 8311.}

\section{DISCUSSION}

We outline five specific challenges that researchers may experience when precepting APPE students remotely, along with possible solutions for each. The challenges and solutions described in this section were identified from personal experience, APPE student feedback, and shared preceptor insights. Solutions are summarized and mapped to example ACPE educational outcomes in Table 1.

\section{Precepting a Short-Duration Research Project}

A research project can take months to years from conceptualization to manuscript publication. Therefore, implementing a four- to six-week research-focused APPE can be challenging for researchers who must sufficiently involve the student pharmacists in a project intended to give them an understanding of what a career in research would be like. Giving students a role in writing a research paper helps them develop the essential skills needed to incorporate research into evidence-based pharmacy practice while providing a competitive advantage to those applying to residences or other postgraduate clinical opportunities. ${ }^{10}$ To address this challenge, our laboratory required each APPE student to complete one well-defined small research deliverable, such as the protocol for a literature review, the introduction section to a full manuscript, or a short commentary. For example, one of our APPE students drafted the background of a clinical research manuscript, while another created a protocol for a scoping review on diabetes medications. We recommend developing an optional plan for APPE students to contribute to a larger research deliverable (eg, a peerreviewed research manuscript) if they wish to continue volunteering with the research team after they transition to other APPEs.

Scoping reviews are larger research deliverables that can be completed by APPE students, as they require students to learn literature review methodology but do not require substantial statistical knowledge or critical appraisal to complete. ${ }^{11}$ During an APPE, students can complete and register a scoping review protocol. Students may wish to continue with the lab as a volunteer, which will give them more time to gain the knowledge needed to make further contributions to the project, such as publish the protocol, complete article screening, and write parts of the manuscript. An alternative to assigning independent research deliverables to APPE students is to involve them in the data collection or data analysis for an ongoing project. In these scenarios, students should also be given opportunities to understand the background of the project and present the results to have sufficient exposure to a broad range of skills required in pharmacist-researcher careers.

\section{Student Pharmacists with Limited Research Experience}

Students entering a research-focused APPE may have little or no previous research experience. To gauge an APPE student's baseline knowledge, a pre-assessment can be assigned that requires students to leverage skills applicable to the research project. For example, if the student will be conducting a literature review, they may be asked to compose a one-page summary of papers that relate to one of the laboratory's focus areas. Through this assessment, students will begin to familiarize themselves with relevant literature while providing the preceptor with insight into their baseline critical appraisal and communication skills. Importantly, the pre-assessment can help align the expectations the preceptor and APPE student have for the APPE as a shared understanding of expectations helps to facilitate productivity and minimize misunderstandings. ${ }^{12}$

We also encourage preceptors to provide APPE students with learning materials that can provide them with basic knowledge of the research field. These materials may include pre-made lecture slides, recorded lectures, and guidance for relevant training (eg, ethics requirements). We recommend that preceptors distribute foundational materials before the APPE begins and any other documents once the student has officially started the APPE to avoid overwhelming students with pre-reading material. Given the remote nature of the APPE, students may be reluctant to reach out to preceptors when they have questions. Therefore, researchers should meet regularly with the student to answer questions about the learning materials. Specifically, preceptors should schedule virtual meetings, provide clear expectations about which learning materials should be reviewed in advance, and ask students to be prepared with well-defined questions for the preceptor to address. In our experience, these regular meetings encourage APPE students to read with intent, as they have set opportunities to discuss concepts that are not clear before applying the acquired knowledge and skills to their research project. Other opportunities for learning introductory research include journal clubs, professional development sessions, and presentation skills assessments.

\section{Maintaining Consistent Communication in a Virtual Environment}

Reliable modes of communication are important when preceptors cannot regularly see students in person. Providing APPE students with a summary of the laboratory's communication platforms helps to prevent confusion and increase student comfort level. For example, our team used different platforms for different types of communication: Slack (Slack Technologies, Inc) for 


\section{American Journal of Pharmaceutical Education 2021; 85 (5) Article 8311.}

Table 1. Challenges and Proposed Solutions for Conducting Remote, Research-Based Advanced Pharmacy Practice Experiences

\begin{tabular}{|c|c|c|}
\hline Challenges & Potential Solutions & Corresponding ACPE Standard \\
\hline Time constraint & $\begin{array}{l}\text { Assign small research deliverables instead of } \\
\text { larger projects. } \\
\text { Involve students in data collection or data analysis } \\
\text { of larger projects. } \\
\text { Provide a voluntary option to continue with a } \\
\text { larger research deliverable. }\end{array}$ & $\begin{array}{l}\text { 3.1. Problem solving and 3.4. Innovation and } \\
\text { entrepreneurship: short research timelines } \\
\text { encourage APPE students to identify problems, } \\
\text { explore viable solutions and apply creative } \\
\text { strategies to accomplish goals in a timely } \\
\text { manner. }\end{array}$ \\
\hline $\begin{array}{l}\text { Maintaining } \\
\text { communication }\end{array}$ & $\begin{array}{l}\text { Provide a breakdown of the online platforms and } \\
\text { communication methods. } \\
\text { Include non-internet dependent (ie, cellular) modes } \\
\text { of communication. } \\
\text { Create a tentative schedule for virtual meetings and } \\
\text { check-ins. } \\
\text { Set response- time expectations for the student and } \\
\text { preceptor. } \\
\text { Collaboratively create a research learning contract. }\end{array}$ & $\begin{array}{l}\text { 3.6. Communication: a plan for reliable modes of } \\
\text { communication will encourage APPE students } \\
\text { to effectively communicate with individuals and } \\
\text { groups. }\end{array}$ \\
\hline
\end{tabular}

quick messaging, Basecamp (Basecamp) for disseminating project documents, and Microsoft Teams (Microsoft Corporation) for meetings. In the case of internet connectivity issues, we recommend that students also have access to at least one non-internet (ie, cellular) mode of communication.

To provide structure, we recommend creating a longterm, tentative schedule for virtual meetings to maintain 


\section{American Journal of Pharmaceutical Education 2021; 85 (5) Article 8311.}

communication throughout the APPE. An established schedule allows students adequate time to prepare for meetings and, in our experience, helps to set expectations for the student and alleviate stress. Additionally, students should be aware of the preceptor's expectations of the student regarding document turnaround times and response times, especially for evenings and weekends. Preceptors should acknowledge that APPE students' daily schedules have likely been impacted by the pandemic and should take into account the students' specific situations when scheduling and setting deadlines. Overall, if detailed guidelines about communication are explained at the beginning of the APPE and enforced consistently throughout it, students tend to be more comfortable and more likely to actively participate in communication with both the preceptor and the team.

One way in which preceptors and APPE students can formally establish these communication preferences and expectations is through a research learning contract. ${ }^{13}$ These contracts help team members to collaboratively articulate short-term and long-term goals, schedules, resources, communication protocols, responsibilities, tasks, outcomes, and more. ${ }^{13}$ When discussed and created together, these research learning contracts help to encourage mutual understanding, trust, accountability, and partnership.

\section{Balancing Mentoring Time Between Graduate Students and APPE Students}

Many preceptors for research-based APPEs are also supervisors of graduate trainees, and therefore must balance their time between several students. To reduce the workload of the preceptor and provide valuable mentorship experience for graduate students, preceptors can provide senior graduate students with the opportunity to mentor APPE students by overseeing certain aspects of their learning. ${ }^{14,15}$ Additionally, multiple mentor interactions during the APPE can provide new insights and experiences for student pharmacists, allowing them to form more connections, develop more skills, and keep the experience engaging. ${ }^{14,15}$ Preceptors should, however, clarify what the graduate student's role will be and delineate which responsibilities fall to the preceptor alone. For example, graduate students can supervise APPE students completing smaller steps of a project; however, the midpoint and final APPE assessments must be conducted by the preceptor, with input from graduate trainees if needed. Additionally, precepting two APPE students simultaneously can provide the student pharmacists with a partner with whom they can collaborate, discuss ideas, and exchange feedback. However, a maximum studentto-faculty ratio of 10:1 should be maintained to facilitate the provision of individualized student feedback based on their contributions to a project to ensure that each student is fairly assessed. ${ }^{6}$

\section{Keeping APPE Students Engaged and Motivated}

Staying focused and on schedule while working from home during a pandemic can be a significant challenge for students who are used to working with peers and directly interacting with patients. Aligning the APPE project with students' interests and career goals can help improve their engagement. Advanced pharmacy practice experiences have predefined educational outcomes; however, at the beginning of the experience, students should reflect on their personal learning objectives and how the APPE can help them achieve their career goals. ${ }^{10}$

Preceptors can not only cater the research project to students' interests but also reach out to their network of colleagues and past alumni who can provide APPE students with insights into different fields and career paths. The APPE students assigned to our laboratory virtually met alumni in government and industry careers who spoke with the students about their day-to-day job responsibilities and career paths, and provided general advice. In our experience, an advantage of working in a virtual environment is that many people are using an online platform in some form, facilitating discussions with those who would normally not have the time or means to commute and participate in in-person talks.

Preceptors can apply several other strategies to help improve student engagement. First, setting an inviting tone at the beginning of the APPE by holding a virtual orientation in which the students are introduced to the research team and their projects may help students feel less isolated and establish themselves as team members. A brief daily check-in where preceptors and APPE students discuss tasks can provide the extra guidance students may need to complete their projects on time. Preceptors should also stay connected with students to discuss their thoughts and concerns during what is likely a stressful time for both parties. Additionally, preceptors should share impromptu opportunities with APPE students to get involved in non-project specific activities. For example, our laboratory invited APPE students to participate in webinars that were part of a university-wide Undergraduate Summer Research Program. Finally, the preceptor should invite feedback from APPE students throughout the rotation and adapt the experience in ways that consider students' suggestions and address students' concerns.

\section{CONCLUSION}

Research-focused APPEs help students to achieve PharmD competencies and grow as professionals, and thus are excellent options for remote practice experiences 


\section{American Journal of Pharmaceutical Education 2021; 85 (5) Article 8311.}

that do not involve direct patient care. Many researchers and first-time preceptors have responded to the increased demand for remote, non-direct patient care APPEs. However, preceptors may feel overwhelmed by changes in their own personal and professional lives due to the pandemic and the increased guidelines and documents that have accompanied the rapid transition to a virtual environment. Identification of common challenges and developing a strategy to address issues before a rotation begins can help to alleviate stress and cultivate a positive environment for both the student and the preceptor.

\section{ACKNOWLEDGMENTS}

We thank Dr. Suzanne Cadarette and PharmD candidates Brittany Salmon and Meagan Hatch for their shared insights on their APPE rotation experiences.

This work was supported by the University of Toronto Leslie Dan Faculty of Pharmacy Summer Undergraduate Research Program (USRP). Dr. Kaleen N. Hayes is supported by a CIHR Doctoral Research Award (GSD-16412), the Drug Safety and Effectiveness Crossdisciplinary Training (DSECT) Program, and the Ontario Drug Policy Research Network (ODPRN).

\section{REFERENCES}

1. United Nations Educational, Scientific and Cultural Organization. School closures caused by Coronavirus (Covid-19). https:// en.unesco.org/covid19/educationresponse. Accessed May 3, 2021. 2. Bambakidis NC, Tomei KL. Impact of COVID-19 on neurosurgery resident training and education. J Neurosurg. 2020;1-2. doi:10.3171/2020.3.JNS20965

3. Fuller KA, Heldenbrand SD, Smith MD, Malcom DR. A paradigm shift in US experiential pharmacy education accelerated by the COVID-19 pandemic. Am J Pharm Educ. 2020;84(6):692-696. doi: 10.5688/ajpe 8149

4. Whelan A, Prescott J, Young G, Catanese VM. Guidance on medical students' clinical participation: effective immediately. Published March 17, 2020. https://www.aamc.org/system/files/
2020-04/meded-April-14-Guidance-on-Medical-StudentsParticipation-in-Direct-Patient-Contact-Activities.pdf. Accessed May 3, 2021.

5. Accreditation Council for Pharmacy Education. Setting the standard in pharmacy education. https://www.acpe-accredit.org/. Accessed May 3, 2021.

6. Accreditation Council for Pharmacy Education. Accreditation Standards and Key Elements for the Professional Program in Pharmacy Leading to the Doctor of Pharmacy Degree ("Standards 2016"). Published February 2015. https://www.acpe-accredit.org/pdf/ Standards2016FINAL.pdf. Accessed May 3, 2021.

7. University of Toronto Leslie Dan Faculty of Pharmacy. For Preceptors - Call for Remote Non-Direct Patient Care (NDPC) APPE Rotations. Published April 2020. https://pharmacy.utoronto.ca/ preceptors-call-remote-non-direct-patient-care-ndpc-appe-rotations. Accessed May 3, 2021.

8. Deal EN, Stranges PM, Maxwell WD, et al. The importance of research and scholarly activity in pharmacy training.

Pharmacotherapy. 2016;36(12):200-205. doi:10.1002/phar.1864

9. Haines SL, Dy-Boarman EA, Clifford KM, et al. Methods used by colleges and schools of pharmacy to prepare student pharmacists for careers in academia. Am J Pharm Educ. 2017;81(1):1-9. doi:10.5688/ ajpe 8116

10. Association of Faculties of Pharmacy of Canada. AFPC Educational Outcomes for First Professional Degree Programs in Pharmacy in Canada 2017. Published June 2017. https://

www.afpc.info/system/files/public/AFPC-Educational\%20Outcomes \%202017_final\%20Jun2017.pdf Accessed May 3, 2021.

11. Arksey H, O’Malley L. Scoping studies: towards a methodological framework. Int J Soc Res Methodol Theory Pract. 2005;8(1):19-32. doi:10.1080/1364557032000119616

12. Handelsman J, Pfund C, Lauffer SM, Pribbenow CM. Entering Mentoring. Madison: The Wisconsin Program for Scientific Teaching; 2005.

13. Mabrouk PA. Research learning contracts: a useful tool for facilitating successful undergraduate research experiences. Counc Undergrad Res Q. 2003:26-30.

14. Roche VF, Limpach AL. A collaborative and reflective academic advanced pharmacy practice experience. Am J Pharm Educ. 2011; 75(6):1-7. doi:10.5688/ajpe756120

15. Morin AK, Jarvis CI, Pesaturo KA, et al. Descriptive report of a team-taught elective academic-focused advanced pharmacy practice experience. Curr Pharm Teach Learn. 2014;6(2):265-276. doi: 10.1016/j.cptl.2013.11.009 